\title{
DEVERES DE PROTEÇÃO PENAL NA PERSPECTIVA DOS TRIBUNAIS INTERNACIONAIS DE DIREITOS HUMANOS
}

\author{
LUCIANO FELDENS *
}

\begin{abstract}
RESUMO: O presente estudo enfoca o tema dos deveres de proteção penal com base nos direitos fundamentais enquanto imperativos de tutela e à luz da jurisprudência dos Tribunais Internacionais de Direitos Humanos.
\end{abstract}

PALAVRAS-CHAVE: Deveres de Proteção Penal, Direitos Fundamentais, Direito Penal.

\begin{abstract}
The theme of the present study focuses on criminal protection duties based on the positive dimension of fundamental rights theory as determined in jurisprudence set forth in international courts of human rights.

KEYWORDS: Criminal Protection Duties, Fundamental Rights, Penal Law.

SUMÁRIO: 1. Considerações introdutórias: o objetivo deste estudo. 2. De Damiens a Damião: Os direitos humanos e fundamentais entre o excesso e a insuficiência da ação estatal: bases empíricas para a discussão do problema. 2.1. O suplício de Damiens (França, 1757). 2.2. O suplício de Damião (Brasil, 1999-2006). 2.3. O Estado e o Direito em tempos de Damiens e de Damião. 3. Deveres estatais de proteção: sua fundamentação teórico-normativa. 3.1. Deveres de proteção na lógica contratualista. 3.2. Deveres de proteção desde a perspectiva constitucional. 3.2.1. Os direitos fundamentais enquanto imperativos de tutela. 3.2.2. A proibição de proteção deficiente (Untermassverbot). 3.2.3. Deveres de proteção de caráter jurídico-penal. 3.3. Deveres de proteção nas Convenções Internacionais de Direitos Humanos: as "obrigações positivas" dos Estados. 4. Concretizações dos deveres de proteção jurídico-penal na jurisprudência dos Tribunais Internacionais de Direitos Humanos. 4.1. O Convênio Europeu para a Proteção dos Direitos Humanos e Liberdades Fundamentais (CEDH, 4.11.1950) e a jurisprudência do Tribunal Europeu de Diretos Humanos (TEDH). 4.2. A Convenção Americana sobre Direitos Humanos (CADH, 22.11.1969) e a jurisprudência da Corte Interamericana de Diretos Humanos (CIDA). 5. O desfecho do Caso Damião na Corte Interamericana de Direitos Humanos. 6. Considerações conclusivas.
\end{abstract}

\section{CONSIDERAÇÕES INTRODUTÓRIAS: O OBJETIVO DESTE ESTUDO}

Entre discursos sérios e outros de distinta qualificação, há muito, no Brasil, e precisamente no meio acadêmico, o Direito penal vem sendo objetificado como um instrumento gerador de violência, manipulado por instituições que, em automática consequiência, tampouco escapam à crítica.

* Professor do Programa de Pós-Graduação em Ciências Criminais da PUCRS; Doutor em Direito Constitucional; Mestre em Direito. Especialista em Direito Penal; Procurador da República. 
Conquanto nos seja possível identificar históricas e recorrentes iniqüidades na operacionalização do Direito penal, convém não sucumbirmos ao perigoso terreno da generalização, o qual, além de cientificamente comprometedor, amplifica uma campanha deslegitimadora do sistema que, quando não reflete uma resistência classista, deixa de oferecer soluções plausíveis à substituição do modelo vigente.

Nesse tom, podem-se dizer escassos os debates acadêmicos que buscam oferecer, com um razoável aprofundamento teórico, uma perspectiva legitimadora da intervenção penal, seja a partir de uma visão de Estado enquanto retrato da civilização - é dizer, da emancipação do Homem e da sociedade em refúgio à barbárie -, seja a partir de um enfoque decorrente da normatividade da Constituição.

É sempre sedutor - e praticamente inevitável - secundar a Radbruch acerca da indeclinável aceitabilidade do Direito penal (democrático e proporcional) como uma espécie de "mal menor”. Mormente em um transcurso da História, como o que vivemos, onde a permanente busca pela resolução de conflitos em arenas comprometidas com o futuro da humanidade (ONU) tem apresentado rotas de fuga, com a repristinação do uso unilateral da força - e, até mesmo, da forca. E o que talvez seja pior: com o fomento de espaços destituídos de qualquer resquício de ilustração, onde Guantánamo e Abu Grahib reprisam, em pleno século XXI, o foucaultiano suplício de Damiens.

O presente ensaio, obediente às naturais limitações que o circundam, colhendo lições da prática jurisdicional humanitária internacional, busca restaurar essa harmonia possível entre os direitos fundamentais e o Direito penal, os quais não apenas podem, senão que devem sintonizar-se em um ambiente comunitário plural voltado à prospecção da liberdade.

2. DE DAMIENS A DAMIÃO: OS DIREITOS HUMANOS E FUNDAMENTAIS ENTRE O EXCESSO E A INSUFICIÊNCIA DA AÇÃO ESTATAL: BASES EMPÍRICAS PARA A DISCUSSÃO DO PROBLEMA

\subsection{O Suplício de Damiens (França, 1757)}

É conhecido o suplício a que foi submetido Damiens, narrado por Foucault na inauguração de seu clássico Vigiar e Punir e aqui sinteticamente reproduzido: "Damiens fora condenado, a 2 de março de 1757, a pedir perdão publicamente diante da porta principal da Igreja de Paris, levado e acompanhado numa carroça, nu, de camisola, carregando uma tocha de cera acesa de duas libras; na dita carroça, na praça de Grève, e sobre um patíbulo que aí será erguido, atenazado nos mamilos, braços, coxas e barrigas das pernas, sua mão direita segurando a faca com que cometeu o parricídio, queimada com fogo de enxofre, e às partes em que será atenazado se aplicarão chumbo derretido, óleo fervente, piche em fogo, cera e enxofre derretidos conjuntamente, e a seguir seu corpo será puxado e desmembrado por quatro cavalos e seus membros e corpo consumidos ao fogo, reduzidos a cinzas. (...) Finalmente, foi esquartejado. Essa última operação foi muito longa, porque os cavalos utilizados não estavam afeitos à tração; de modo que, em vez de quatro, foi preciso colocar seis; e como isso não bastasse, foi necessário, para desmembrar as coxas do infeliz, cortar-lhe os nervos e retalhar as juntas... (...) Acendeu-se o enxofre, mas o fogo era tão fraco que a pele das costas da mão mal e mal sofreu. Depois, um executor, de mangas 
arregaçadas acima dos cotovelos, tomou umas tenazes de aço preparadas ad hoc, medindo cerca de um pé e meio de comprimento, atenazou-lhe primeiro a barriga da perna direita, depois a coxa, daí passando às duas partes da barriga do braço direito; em seguida os mamilos. Este executor, ainda que forte e robusto, teve grande dificuldade em arrancar os pedaços de carne que tirava em suas tenazes duas ou três vezes do mesmo lado ao torcer, e o que ele arrancava formava em cada parte uma chaga do tamanho de um escudo de seis libras. Depois desses suplícios, Damiens, que gritava muito sem, contudo, blasfemar (...) Os cavalos deram uma arrancada, puxando cada qual um membro em linha reta, cada cavalo segurado por um carrasco. (...) Depois de duas ou três tentativas, o carrasco Samson e o que lhe havia atenazado tiraram cada qual do bolso uma faca e lhe cortaram as coxas na junção com o tronco do corpo; os quatro cavalos, colocando toda força, levaram-lhe as duas coxas de arrasto (...) a seguir, fizeram o mesmo com os braços (...) Uma vez retiradas essas quatro partes, desceram os confessores para lhe falar; mas o carrasco informou-lhes que ele estava morto (...) Em cumprimento da sentença, tudo foi reduzido a cinzas”. ${ }^{1}$

\subsection{O Suplício de Damião (Brasil, 1999-2006)}

Passados dois séculos e meio de Damiens, o Brasil protagoniza, ainda que sob antagônica perspectiva, semelhante violação de direitos humanos. A vítima imediata: o brasileiro Damião Ximenes Lopes, portador de acentuada deficiência mental, torturado até à morte em estabelecimento destinado a tratamento psiquiátrico (Casa de Repouso de Guararapes, centro de atendimento privado que operava no âmbito do Sistema Único de Saúde), no município de Sobral/CE. No dia 4 de outubro de 1999, três dias após a internação de Damião, sua mãe encontrou-o agonizando na clínica; pediu socorro ao médico, porque acreditava que seu filho, devido às condições que apresentava, estava prestes a falecer. O médico, no entanto, não atendeu seu pleito. E Damião morreu nesse mesmo dia. Seu cadáver exteriorizava marcas de tortura: seus punhos estavam dilacerados e completamente roxos; suas mãos estavam perfuradas e uma parte do seu nariz, danificada. Ainda assim, a causa mortis foi atestada como "morte natural, parada cardio-respiratória”. O cadáver de Damião foi então levado para Fortaleza, a fim de que fosse realizada uma necropsia, a qual atestaria "morte indeterminada”. A família, incrédula quanto ao laudo, sustentou que houvera manipulação e omissão da verdade. As lesões encontradas no corpo de Damião são lesões consideradas pelo Protocolo de Istambul como lesões típicas de traumas costumeiramente verificados em corpos de pessoas submetidas à tortura. Por insistência do Ministério Público houve uma reavaliação do laudo, onde finalmente atestou-se que a morte de Damião fora causada por lesões traumáticas (equimoses, escoriações e hematomas, lesões essas causadas por objetos contundentes), que poderiam ter sido ocasionadas por socos, pedradas ou pontapés.

O suplício de Damião ainda se trasladaria, pois, a sua família. No dia de seu óbito, sua irmã registrou ocorrência na Delegacia de Polícia da Sétima Região de Sobral. A Polícia, entretanto, "não se interessou pelo caso". ${ }^{2}$ Diante dessa circunstância, o

\footnotetext{
${ }^{1}$ FOUCAULT, Michel. Vigiar e Punir, 19a ed., Petrópolis: Vozes, 1999, p. 9-10.

${ }^{2}$ Referência constante na Sentença da Corte Interamericana de Direitos Humanos no Caso Damião, na parte em que sintetiza o depoimento de sua irmã, Irene Ximenes Lopes Miranda.
} 
episódio foi denunciado perante a Comissão de Direitos Humanos da Assembléia Legislativa. De nada adiantou. Passados algo em torno de cinco anos, o assassinato de Damião continuava impune em todas as instâncias. No âmbito do processo penal, apontava-se a inexistência de diligências reputadas necessárias à conclusão do mesmo.

A inércia das autoridades brasileiras fez a família recorrer à Comissão Interamericana de Direitos Humanos. Após ampla investigação, a Comissão indicou que teria havido, em relação à morte de Damião: a) falta de efetividade do processo interno de apuração de responsabilidades decorrente da omissão de autoridades, que deixaram de realizar ações e investigações fundamentais para recolher as provas possíveis no sentido de determinar a verdade dos fatos; b) irregularidades na investigação policial que comprometeram a elucidação da morte da vítima; c) inexistência, pois, de uma investigação imediata, séria e exaustiva; e d) inexistência de uma sentença de primeira instância, mesmo depois de passados seis anos da morte violenta da vítima.

Nesses termos, o caso foi admitido pela Corte Interamericana de Direitos Humanos. Sobre a respectiva decisão, que condenou o Brasil por violação de direitos humanos, comentamos mais adiante.

\subsection{O Estado e o Direito em Tempos de Damiens e de Damião}

São inúmeras as diferenças entre Damiens e Damião. E não é por outra razão que fotografamos, lado a lado, esses dois episódios que formam nossa base ilustrativa. Ao fazê-lo, desejamos enfatizar que à diferença de Damiens, em Damião a ilicitude não corre por conta do excesso estatal na aplicação de uma tal ou qual sanção penal; deriva, ao revés, da omissão do Estado na investigação do fato e na punição dos responsáveis. Assim apresentados, os casos oportunizam-nos aduzir uma análise reflexiva acerca da evolução (dos limites) do papel do Estado - e, por conseguinte, do Direito - na restrição, no respeito e na promoção daquilo que hoje concebemos como direitos humanos e fundamentais.

O exemplo foucaultiano contém as digitais de uma França pré-revolucionária, onde a violência oficial campeava desprovida de freios inibitórios aptos a sindicá-la sob uma perspectiva humanitária. Embora em declínio, as marcas do Ancien Régime ainda se faziam observar. Manejado por uma monarquia absolutista onde o soberano concentrava todo o poder desde uma autoridade política "natural", o sistema penal postava-se em contradição com os princípios básicos da nova filosofia (secularização, racionalismo, utilitarismo). A condenação dos rituais de tortura, à base do pensamento penal iluminista, encontrava-se ainda em gestação. ${ }^{3}$ E mais. Enquanto proposta filosófica,

${ }^{3}$ MONTESQUIEU e BECCARIA seriam os expoentes da difusão, na Europa, de uma nova visão de Direito penal assentada nos pressupostos ideológicos da Ilustração. De l'espirit des lois vem à luz em 1748, trazendo, de forma genérica, um conjunto de máximas ou regras para a resolução do problema penal e seus excessos. E um desenvolvimento mais específico da filosofia racional, em sua projeção sobre o Direito penal, com a condenação do uso da tortura e da pena de morte, a partir da noção de que "a pena justa é a pena necessária”, se faria marcar em 1764, com a publicação de Dei delitti e delle pene. Nesse mesmo contexto histórico, em 1763 a crítica acerca da pena capital já se vislumbrava em VOLTAIRE (Traité sur la Tolérance). Também PHILIPON DE LA MADELAINE comporia, em 1770, uma monografia dedicada ao problema da pena de morte (Discours sur la necesité et les moyens de suprimer les peines capitales), a qual se inaugurava com a observação de que na Europa, na segunda metade do século XVIII, contavam-se mais de quarenta crimes 
a limitação dessas práticas encerrava um tormentoso dilema: de um lado, o racionalismo (jurídico) propugnava o monopólio da força nas mãos do Estado e, com isso, o fortalecimento do poder absoluto; por outro, a crítica ao sistema então vigente exigia limitar a arbitrária faculdade punitiva do poder. Era preciso, pois, fortalecer o Estado e, ao mesmo tempo, limitá-lo. ${ }^{4}$

A História nos dá conta de que uma proposição de tal magnitude não se alcançaria sem mais... De momento, e no dever de síntese que nos acompanha, basta-nos assinalar que esses ideais (carta de direitos e divisão de poderes) se encontrariam, ainda que como orientação principiológica, no desenvolvimento de um conceito e, sobretudo, de um sentido de Constituição, o que apenas se lograria obter, na Europa, com a Declaração dos Direitos do Homem e do Cidadão (1789). ${ }^{5}$

Os tempos de Damião são outros; são tempos de consolidação de direitos humanos e de Constituição; de conquistas históricas tampouco alcançadas de maneira incruenta. O pensamento jusfilosófico não se mostraria indiferente à barbárie. A trágica experiência da Segunda Guerra houve por tremular as bases de um positivismo acrítico, ainda permissivo à incubação de leis manifestamente injustas. ${ }^{6}$ Na desafiante proclamação de Adorno, "não repetir Auschwitz erigiu-se em um novo imperativo categórico". Nessa senda, a prospeç̧ão universal dos direitos humanos (logicamente, em termos de Ocidente), especialmente pós-1945, fixaria pontos de não-retorno, os quais seriam incorporados ao novo constitucionalismo que ali nascia como freio à barbárie do autoritarismo nazifascista. Em paralelo à tarefa de reconstrução continental, a Europa

que se pagavam com o sangue do culpado. A respeito, veja-se: PRIETO SANCHÍS, Luis, "La Filosofía Penal de la Ilustración”, in História de los Derechos Fundamentales, Tomo II - Siglo XVIII, Vol. II La Filosofía de los Derechos Humanos, PECES-BARBA MARTÍNEZ, Gregorio et alii (directores), Madrid: Dykinson, 2001, p. 210-216. Ainda sobre o Direito penal em tempos de monarquia absoluta, vejase o monumental estudo: TOMÁS Y VALIENTE, Francisco, "El Derecho Penal de la Monarquía Absoluta (Siglos XVI, XVII y XVIII), in Obras Completas - I, Madrid: Centro de Estudios Políticos y Constitucionales, p. 191-545.

${ }^{4}$ PRIETO SANCHÍS (2001).

${ }^{5}$ Declaração dos Direitos do Homem e do Cidadão (26.08.1789): "XVI - toda sociedade onde a garantia de direitos não esteja assegurada, e na qual a separação de poderes não esteja determinada, não tem Constituição”.

${ }^{6}$ À causa disso, sustentaria Radbruch que a legislação, conquanto formalmente perfeita, porque editada conforme as regras procedimentais, poderia estar em tamanha contradição com a idéia de justiça que perderia completamente sua vinculatividade. São várias as publicações que difundem o que ficou conhecido como cláusula Radbruch. Na língua portuguesa encontra-se o texto intitulado "Cinco Minutos de Filosofia”, escrito imediatamente após a Guerra, ainda em 1945, e publicado, como Apêndice, em RADBRUCH, Gustav, Filosofia do Direito, trad. Cabral de Moncada, Coimbra: Armênio Amado, 1979, p. 415-418. Essa passagem da literatura de Radbruch indicaria, para muitos, uma ruptura na sua filosofia positivista. Entretanto, como alerta Kaufmann, já em 1919 Radbruch apostrofara o positivismo como uma "idolatria do poder"; e mesmo antes disso, em 1914, assentara que "não se pode conceber nenhuma justificação para a vigência do direito manifestamente injusto”. KAUFMANN, Arthur, Filosofia do Direito, Lisboa: Fundação Calouste Gulbenkian, 2004, p. 64. Também sobre o tema: VASSALI, Giuliano, Formula di Radbruch e Diritto Penale, Milano: Giuffrè, 2001; ALEXY, Robert, Derecho Injusto, Retroactividad y Principio de Legalidad Penal - La doctrina del Tribunal Constitucional alemán sobre los homicidios cometidos por los centinelas Del Muro de Berlín, Doxa, Cuadernos de Filosofía del Derecho, 23:2000, pp. 197-230; SCHOLLER, Heinrich, "Princípio da proporcionalidade nos Direitos Constitucional e Administrativo da Alemanha”, Revista do Tribunal Regional Federal da $4^{a}$ Região, Porto Alegre, v. 11, n 38, 2000, p. 230. 
inaugurava a segunda fase do Estado Constitucional. A Constituição, agora com garantias de rigidez material, ofereceria amplos catálogos de direitos fundamentais, civis, sociais, políticos e processuais. ${ }^{7}$ Abria-se, paralelamente, o campo à justiça constitucional, cuja dinâmica apontaria para novas vias de proteção dos direitos: exigência de proporcionalidade de leis, extensão dos direitos fundamentais a todas as leis que lhes afetem (efeito de irradiação) e, inclusive, imposição ao Parlamento de uma atividade legislativa quando sua ausência provoque a desproteção dos direitos. ${ }^{8}$

Sob esse panorama, em tempos de Damião o Leviatã já está encilhado; ademais, tem seus condutores escolhidos pelo povo à base de compromissos superiores (Estado Democrático de Direito). Reclama-se, agora, por prestações positivas (Estado Social), as quais permitam tornar realidade, na maior medida possível, e ao maior número de pessoas, as promessas encartadas nas Declarações e Constituições que marcam a História da segunda metade do Século XX.

Nessa perspectiva, como nos explica Sarlet, assume relevo a função atribuída aos direitos fundamentais desenvolvida com fundamento em um dever geral de efetivação na forma de deveres de proteção (Schutzplichten) do Estado, incumbindo-lhe zelar, inclusive preventivamente, pela proteção dos direitos fundamentais perante seus virtuais agressores. ${ }^{9}$ É sobre esse ponto que nos dedicamos a seguir.

\section{DEVERES ESTATAIS DE PROTEÇÃO: SUA FUNDAMENTAÇÃO TEÓRICO-NORMATIVA}

\subsection{Deveres de Proteção na Lógica Contratualista}

Os deveres estatais de proteção apresentam-se como a versão atual da contraprestação imputada ao - e assumida pelo - Estado em decorrência de um hipotético pacto de sujeição a que aderem os homens no precípuo desiderato de resguardarem sua liberdade e segurança no convívio social. A legitimidade do Estado, que se origina dessa adesão mútua, apenas se perfaz nessa troca.

Em Hobbes, como é sabido, o homem, submetido ao perigo do iminente conflito derivado do desejo ilimitado de apoderar-se de todos bens (da luta "de todos contra todos”), decide renunciar à sua soberania (Estado Natureza) para receber direitos do Estado. A esse respeito, propunha Hobbes que a causa final ou desígnio dos homens (que naturalmente apreciam a liberdade e o domínio sobre os demais), ao introduzirem essa restrição sobre si mesmos (formando Estados), é o cuidado com sua própria conservação e com uma vida mais harmônica (satisfeita), ou seja, o desejo de abandonar aquela mísera condição de guerra, conseqüência necessária das paixões naturais dos homens quando não há um poder visível capaz de mantê-los em respeito. Claro está, para Hobbes, que os pactos que não descansam na espada (na força) não

\footnotetext{
${ }^{7}$ RIVERA BEIRAS, Iñaki. Política Criminal Y Sistema Penal - Viejas y Nuevas Racionalidades Punitivas, Barcelona: Anthropos, 2005, p. 9.

${ }^{8}$ AJA, Eliseo. "Introducción al Concepto Actual de Constitución”, in LASSALE, Ferdinand, ¿Qué és una Constitución?, Barcelona: Ariel, 2001, p. 55.

${ }^{9}$ SARLET, Ingo Wolfgang. "Constituição e proporcionalidade: o direito penal e os direitos fundamentais entre a proibição do excesso e de insuficiência”, Revista Brasileira de Ciências Criminais, n. 47, ano 12, março-abril de 2004, p. 92-93.
} 
passam de palavras sem substância para dar segurança a ninguém. Nesses termos, e apesar das "leis naturais" (como justiça, eqüidade, etc, que cada qual respeita quando tem vontade de fazê-lo), se não for instituído um poder suficiente a garantir nossa segurança, cada um confiará - e poderá legitimamente confiar - apenas em sua própria força para proteger-se frente os demais. ${ }^{10}$

Enfim, como sublinha Alexy, os direitos a prestações em sentido estrito, correlatos aos deveres estatais de tutela, parecem encontrar sua fundamentação no marco do modelo contratualista clássico. A renúncia ao direito a uma efetiva autoproteção condicionada pela transição da situação pré-estatal à situação estatal apenas se justificaria racionalmente se o indivíduo, em troca desta renúncia, obtivesse uma efetiva proteção do Estado. ${ }^{11}$

\subsection{Deveres de Proteção desde a Perspectiva Constitucional ${ }^{12}$}

\subsubsection{Os Direitos Fundamentais Enquanto Imperativos de Tutela}

Analisados desde sua concepção originária, os direitos fundamentais garantem aos indivíduos uma zona de liberdade de atuação imune aos ataques provenientes dos poderes públicos. Nessa perspectiva tradicional, própria de um modelo liberal clássico, os direitos fundamentais projetam-se exclusivamente em face do Estado, impondo-lhe obrigações negativas, de abstenção (proibição de intervenção) nas esferas por eles acobertadas. Funcionam essencialmente, pois, como direitos de defesa frente ao Estado.

Sem embargo, na medida em que o Estado liberal de Direito evolui para formas de Estado social de Direito os direitos fundamentais dinamizam sua própria significação, deixando de figurar como meros limites ao exercício do poder político para se tornarem um conjunto de fins diretivos da ação positiva dos poderes públicos. ${ }^{13}$ Nesses termos, para além de sua dimensão negativa, passam a operar como valores objetivos que orientam por inteiro o ordenamento jurídico, reclamando, dentro da lógica do Estado Social, prestações positivas destinadas a sua proteção.

Esta construção teórica destaca a dupla função dos direitos fundamentais na atualidade: a) por um lado, subsistiria sua condição clássica de direitos subjetivos, ou seja, de direitos de defesa do particular frente ao Estado (aspecto negativo), impondo-se a este a obrigação de abster-se de intervenções desproporcionais no âmbito dos direitos fundamentais (concepção tradicional); b) por outro lado, os direitos fundamentais operariam em sua dimensão objetiva, ${ }^{14}$ isto é, como imperativos de tutela, exigindo

${ }^{10}$ Transcrição adaptada de trechos da obra de HOBBES nas versões em espanhol e português: HOBBES, Thomas, Del Ciudadano y Leviatán, Madrid: Tecnos, 2002, e HOBBES, Thomas, Leviatã - ou Matéria, Forma e Poder de um Estado Eclesiástico e Civil, São Paulo: Martin Claret, 2003.

${ }^{11}$ ALEXY, Robert. Teoria de los Derechos Fundamentales, Madrid: Centro de Estudios Constitucionales, 1997, p. 440-441.

12 Para um aprofundamento do tema tomamos a liberdade de remeter o leitor ao nosso: FELDENS, Luciano, A Constituição Penal - A Dupla Face da Proporcionalidade no Controle de Normas Penais, Porto Alegre: Livraria do Advogado, 2005.

${ }^{13}$ PEREZ LUÑO, Antonio E. Los Derechos Fundamentales, Madrid: Tecnos, 2005, p. 21.

${ }^{14}$ Esse entendimento foi sufragado pelo Tribunal Constitucional alemão no conhecido "Caso Lüth". "os direitos fundamentais estão direcionados, em primeiro plano, a assegurar aos indivíduos a esfera de 
uma atuação ativa (positiva) do Estado, obrigando os poderes públicos a agirem de forma adequada na realização efetiva (proteção eficiente) dos direitos fundamentais mediante um conjunto de prestações. ${ }^{15}$

A atribuição de um caráter jurídico-objetivo aos direitos fundamentais gera para essa categoria normativa uma perspectiva expansiva, uma carga eficacial que, irradiando-se sobre todos os âmbitos do ordenamento jurídico, projeta-se inclusive sobre aqueles que, historicamente, demonstram-se como seus principais “inimigos": o legislador e o indivíduo. ${ }^{16}$ Nesses termos, um tal dever de proteção do direito fundamental pressupõe a adoção de medidas estatais de diversos signos (legislativas, inclusive) frente a ameaças provenientes de terceiros, inclusive de pessoas ou poderes que não são propriamente ou tradicionalmente - os destinatários diretos dos direitos fundamentais. ${ }^{17}$

No âmbito das relações entre particulares ${ }^{18}$ - precisamente onde se estabelecem, em grande escala, as violações a direitos fundamentais -, o ponto central da função de imperativo de tutela é rigorosamente este: o de protegê-los diante de intervenções fáticas por parte de outros sujeitos de direito privado, assegurando-se sua efetiva capacidade funcional. ${ }^{19}$

O Estado é obrigado, em decorrência do dever de proteção derivado dos direitos fundamentais, “a forçar a omissão de uma ação ameaçadora dos respectivos direitos fundamentais oriunda de terceiros”. Isso se dá (ou haveria de se dar), sobretudo, de

liberdade privada de cada um contra intervenções do poder público; são direitos de resistência do cidadão frente ao Estado (...) Da mesma forma é correto, entretanto, que a Grundgesetz, que não pretende ser um ordenamento neutro do ponto de vista axiológico, estabeleceu também, em seu capítulo dos direitos fundamentais, um ordenamento axiológico objetivo, e que, em função deste, ocorre um aumento da força jurídica dos direitos fundamentais (...) Esse sistema de valores, que tem como ponto central a personalidade humana e sua dignidade, que se desenvolve livremente dentro da comunidade social, precisa valer enquanto decisão constitucional fundamental para todas as áreas do direito; Legislativo, Executivo e Judiciário recebem dele diretrizes e impulsos” (BVerfGE 7, 198, 15.01.1958).

${ }^{15}$ A jurisprudência do Tribunal Constitucional espanhol é explícita no reconhecimento desse duplo caráter dos direitos fundamentais, ressaltando os efeitos derivados dessa construção dogmática: “de la significación y finalidades de estos derechos dentro del orden constitucional se desprende que la garantía de su vigencia no puede limitarse a la posibilidad del ejercicio de pretensiones por parte de los individuos, sino que ha de ser asumida también por el Estado (...) los derechos fundamentales no incluyen solamente derechos subjetivos de defensa de los individuos frente al Estado y garantías institucionales, sino también deberes positivos por parte de este" (STC 53/1985, F.J. 4).

${ }^{16}$ Segundo Häberle, tanto o legislador, como o indivíduo, estão limitados pelo mesmo conceito: a função social dos direitos fundamentais. Isso não é uma casualidade. O legislador e o indivíduo são os dois inimigos clássicos, potenciais e atuais, do Direito e da liberdade. HÄBERLE, Peter, La Garantía del Contenido Esencial de los Derechos Fundamentales, Madrid: Dykinson, 2003, p. 13.

${ }^{17}$ HESSE, Konrad. Grundzüge des Verfassungsrechts der Bundesrepublik Deutscchland (Elementos de Direito Constitucional da República Federal da Alemanha), trad. Luís Afonso Heck, Porto Alegre: Fabris, 1998, p. 278.

${ }^{18}$ Sobre o tema, veja-se a mais aprofundada bibliografia: BILBAO UBILLOS, Juan Maria, La Eficácia de los Derechos Fundamentales Frente a Particulares, Madrid: Centro de Estúdios Políticos y Constitucionales, 1997. No Brasil: SARMENTO, Daniel. Direitos Fundamentais e Relações Privadas, 2. ed., Rio de Janeiro: Lumen Juris, 2006.

${ }^{19}$ E como anota Canaris, uma necessidade de proteção, em casos tais, há de ser reconhecida sobretudo se essas intervenções forem ilícitas, juízo esse que resulta da própria Constituição. CANARIS, Claus-Wilhelm, Direitos Fundamentais e Direito Privado, trad. Ingo Wolfgang Sarlet e Paulo Mota Pinto, Coimbra: Almedina, 2003, p. 107. 
forma preventiva, pelo Poder Legislativo, como destinatário imediato do dever de proteção, sem que estejam desobrigados a tanto, em suas respectivas esferas de competência, os demais Poderes de Estado. ${ }^{20}$ Nessa perspectiva, ao legislador não mais podemos vê-lo exclusivamente como "sujeito passivo" dos direitos fundamentais; corresponde-lhe, paralelamente, uma função ativa, de integração do direito, é dizer, de dotá-lo de um perfil final e específico a partir de um enunciado que lhe confere existência. ${ }^{21} 22$

\subsubsection{A Proibição de Proteção Deficiente (Untermassverbot)}

Como decorrência lógica da função de imperativo de tutela que colore os direitos fundamentais avulta a necessidade de que uma tal proteção há de se realizar de modo a satisfazer exigências mínimas de tutela. Afinal, como pontua Canaris, um dever de tomar medidas ineficazes não teria qualquer sentido. ${ }^{23}$ Entra em questão, aqui, a proibição de proteção deficiente (Untermassverbot) ${ }^{24}$, categoria que encerra uma aptidão operacional que permite ao intérprete determinar se um ato estatal eventualmente retratado em uma omissão, total ou parcial - vulnera um direito fundamental. ${ }^{25}$ Nessa perspectiva, opera como ferramenta dogmática extraída do mandado de proporcionalidade e que nessa condição predispõe-se a funcionar como um parâmetro no controle (de constitucionalidade) de determinados atos estatais que eliminem ou deixem de concretizar a proteção necessária ao adequado e eficaz desenvolvimento do direito fundamental.

A eficácia da proteção integra, em tal contexto, o próprio conteúdo do dever de proteção, embora com este não se confunda. Enquanto no dever de proteção indagamos sobre o "se" da (necessidade) de proteção, a proibição de insuficiência tematiza o "como" essa proteção deve efetivar-se de modo a permitir a realização do direito fundamental. ${ }^{26}$

${ }^{20}$ MARTINS, Leonardo, Cinqüenta Anos de Jurisprudência do Tribunal Constitucional Federal Alemão, Konrad-Adenauer-Stiftung E.V., 2005, p. 83-84.

${ }^{21}$ CRUZ VILLALÓN, Pedro, in Temas Básicos de Derecho Constitucional (Manuel Aragón Reyes, coord.), Tomo III, Madrid: Civitas, 2001, p. 109.

${ }^{22}$ Como sustenta Jiménez Campo, “al poder público no le exige la Constitución sólo ‘respeto’ (no transgresión) del derecho fundamental; la Constitución dice que los derechos vinculan, y en esta expresión entran, sin duda, deberes positivos de diverso signo, fundamentados siempre en una visión de los derechos fundamentales no limitada a su imagen primordial de derechos subjetivos, sino abarcante también de su condición ordenadora, en un sentido objetivo, de toda la convivencia jurídica”. Assim que "sobre el legislador pesa el deber de realizar los derechos fundamentales en la íntegra vida comunitaria”, dever este que "exigirá, en unos casos, una acción pública de promoción de condiciones y medios para el efectivo disfrute del derecho y, en otras ocasiones, su protección legal frente a agresiones que provengan de quienes no son 'poderes públicos’”. JIMÉNEZ CAMPO, Derechos Fundamentales. Concepto y Garantías, Madrid: Trotta, 1999, p. 30. ${ }^{23}$ CANARIS (2003:123).

${ }^{24}$ A expressão Untermassverbot foi cunhada por Canaris, e posteriormente incorporada pelo Tribunal Constitucional alemão. Engendrando matizes identificados ao mandado de proporcionalidade, se antagonizaria, com algumas adaptações, à tradicional proibição de excesso. Na síntese do Bundesverfassungsgericht, em uma segunda famosa decisão sobre o tema do aborto, "caso não pretenda violar a proibição da proteção deficiente, a configuração da tutela por parte do ordenamento jurídico deve corresponder a exigências mínimas” (BverfGE 88, 28.05.1993). Sobre o tema, mais detidamente: FELDENS (2005).

${ }^{25}$ BERNAL PULIDO, Carlos. El Principio de Proporcionalidad y los Derechos Fundamentales, Madrid: Centro de Estudios Políticos y Constitucionales, 2003, p. 799. Note-se a respeito que, mutatis mutandis, a proibição de proteção deficiente conta com a mesma estrutura geral que a proibição do excesso. Idem, p. 800-803.

${ }^{26}$ CANARIS (2003: 122). 
Na precisa síntese do Tribunal Constitucional alemão: “O Estado deve adotar medidas normativas e fáticas suficientes para cumprir seu dever de tutela, que levem - considerando os bens conflitantes - ao alcance de uma proteção adequada e, como tal, efetiva (proibição de insuficiência). Para tanto, é necessário um projeto de proteção que combine elementos de proteção preventiva e repressiva. (...) A proibição de insuficiência não permite a livre desistência da utilização, também, do direito penal e do efeito de proteção de vida humana dele decorrente. (...) É tarefa do legislador determinar, detalhadamente, o tipo e a extensão da proteção. A Constituição fixa a proteção como meta, não detalhando, porém, a sua configuração. No entanto, o legislador deve observar a proibição de insuficiência; até aqui, ele está sujeito ao controle jurisdicional constitucional”. ${ }^{27}$

\subsubsection{Deveres de Proteção de Caráter Jurídico-Penal}

Uma vez afirmada a existência de deveres de proteção suficiente que pesam sobre os Estados, torna-se meridianamente compreensível, e juridicamente argumentável, que essa atividade integradora (concretizadora) dos direitos fundamentais, haverá de passar, em determinado momento e medida, pelo sistema jurídico-penal. ${ }^{28}$ Como assinala Häberle, é tão evidente a necessidade uma intervenção do legislador penal em determinados setores que, "se carecêssemos de leis penais, os direitos fundamentais e a Constituição seriam supérfluos. No lugar da liberdade dominariam a arbitrariedade e a força; no lugar do ordenamento comum gerador de unidade (Hesse) a que a Constituição aspira, haveria desintegração e anarquia. Os direitos fundamentais não teriam nenhuma importância para a vida social em seu conjunto. O ser pessoal e o ser social seriam, em igual medida, impossíveis". ${ }^{29}$

De fato, em situações determinadas - ou determináveis, a partir de una específica realidade contextual (social, espacial e temporal) - a ausência de adequada proteção normativa coloca em xeque a própria subsistência do direito no âmbito comunitário. Nesse tom, não incorremos em nenhum exagero ao afirmar que a proteção jurídico-penal se afigura como uma condição eventualmente necessária - ainda que insuficiente à plena realização do direito fundamental. No exemplo de Rubio Llorente: “é óbvio que o direito à vida ou à liberdade pessoal não existiriam no seio da sociedade se o Estado não os protegesse mediante as normas que sanciona o homicídio, o seqüestro etc”. ${ }^{30}$ Essa constatação é compartida, e ratificada, por amplos e importantes setores da doutrina constitucional; por Díez-Picazo, por exemplo: “às vezes, a proteção de certos direitos fundamentais - e, em geral, de determinados valores constitucionalmente relevantes - somente pode ser efetiva se realizadas pela via penal”. 31 Também Canotilho

${ }^{27}$ (BVerfGE, 88, 203). Adaptado da tradução de MARTINS (2005).

${ }^{28}$ Sobre essa hipótese, assim decidiu o Bundesverfassungsgericht, na decisão conhecida como Aborto I: "nos casos extremos, quando a proteção determinada pela Constituição não se consiga de nenhuma outra maneira, o legislador pode estar obrigado a recorrer ao Direito penal para proteger a vida em desenvolvimento" (BverfGE 39, 1). Livre tradução do alemão recolhida do texto de KAYBER, Marijon, "Sobre el Potencial Incriminador de los Princípios Limitadores del Derecho Penal. Competencias Penales en la Cuestión del Aborto”, in La Insostenible Situación del Derecho Penal, Granada: Comares, 1999, p. 151.

${ }^{29}$ HÄBERLE (2003: 175-176).

30 RUBIO LLORENTE, Francisco. “Los Deberes Constitucionales”, Revista Española de Derecho Constitucional, a. 21, $\mathrm{n}^{\circ}$ 62, may./ago. 2001.

${ }^{31}$ DÍEZ-PICAZO, Luis María. Sistema de Derechos Fundamentales, Madrid: Civitas, 2003, p. 403. 
observa que muitas normas da Constituição consagram direitos dos indivíduos a ações positivas do Estado, quer reconhecendo os direitos a uma ação positiva de natureza fática, quer garantindo o direito a um ato positivo de natureza normativa. Como exemplo deste, o professor português aponta o "direito à protecção do direito à vida através de normas penais, emanadas no Estado”. 32

O dever de proteção jurídico-penal, tal como o perspectivamos, parte da mesma lógica contratualista segundo a qual, salvo em situações de cautelaridade (legítima defesa, estado de necessidade), o Estado detém o monopólio da força. Sob tal premissa, compete ao Estado: a) enquanto Poder Legislativo, a elaboração - ou manutenção, se já existentes - de disposições jurídico-penais (quando justificada sua necessidade) à tutela dos direitos fundamentais; b) enquanto Poder Executivo, imprimir, mediante o seu poder de polícia, a necessária investigação tendente à elucidação e punição dos atentados criminais ao direito fundamental; c) enquanto Poder Judiciário, oferecer uma tutela judicial efetiva na apreciação das ofensas submetidas à sua avaliação.

Em conexão com o que vimos sustentando, cabe recordar que em muitas ocasiões as normas de direito público que supõem uma ingerência no âmbito protegido por um direito fundamental têm por objeto a proteção do direito subjetivo de determinadas pessoas, e não apenas a promoção de um interesse público objetivo. A dimensão social que assumem os direitos fundamentais torna possível a conjugação de ambos os objetivos. ${ }^{33}$ É justamente o que sucede no âmbito do Direito penal, particularmente quando suas disposições estão dirigidas à tutela de um direito fundamental exposto a uma potencial agressão. Na hipótese, do outro lado da relação - nunca convém que esqueçamos - encontra-se o titular de um direito fundamental que o Estado - e muito particularmente o legislador - tem a obrigação de proteger. E mais. Nestes casos, o interesse público perseguido é imanente a (ou consiste precisamente na) proteção jurídico-legal do direito fundamental ameaçado, uma proteção este que, uma vez conferida, passa a formar parte do próprio conteúdo do direito fundamental, tal como manifestado pelo Tribunal Constitucional espanhol: "el legislador puede proteger los derechos fundamentales penalmente, y en tal caso, no es posible desconocer que la protección penal forma parte del derecho fundamental mismo". ${ }^{4}$

3.3. Deveres de Proteção nas Convenções Internacionais de Direitos Humanos: as “Obrigações Positivas” dos Estados

A teoria dos deveres de proteção dos direitos fundamentais, quando reconduzida ao plano dos direitos humanos, encontra sua formulação congênere na doutrina das positive obligations (obrigações positivas). Essa é a terminologia adotada pela Corte Interamericana de Direitos Humanos e pelo Tribunal Europeu de Direitos Humanos na análise das implicações que pesam sobre os Estados na tutela dos direitos recuperados

\footnotetext{
${ }^{32}$ CANOTILHO, Direito Constitucional e Teoria da Constituição, 4. ed., Coimbra: Almedina, p. 1219.

${ }^{33}$ Sequer a liberdade pode ser metafisicamente considerada como una "essência”. Liberdade é - e sempre será - "liberdade-em” (sociedade). Sobre o tema: HEIDEGER, Martin, Ser e Tempo, Parte I, 13. ed., Petrópolis: Vozes, 2004, p. 184-194. Desde uma perspectiva da dogmática constitucional, "el derecho fundamental de libertad es multidimensional, es también libertad en la sociedad, sólo se realiza desde condiciones sociales determinadas, se afirma frente a los grupos, requiere una estructura” (I. Otto). BILBAO UBILLOS (1997). ${ }^{34}$ (STC 71/1984, F. J. 2).
} 
nas respectivas Convenções (Convenção Americana sobre Direitos Humanos e Convênio Europeu para a Proteção dos Direitos Humanos e Liberdades Fundamentais).

Essas obrigações positivas desdobram-se nos planos substantivo e procedimental, projetando-se sobre os ordenamentos jurídicos penais e processuais de cada Estado. Segundo a orientação dessas Cortes Internacionais, a efetivação dos Direitos do Homem exige tanto uma legislação adequada a promover a dissuasão de atos atentatórios às liberdades fundamentais, como uma atuação efetiva (positiva) na investigação desses fatos e, em sendo o caso, na imposição de sanção aos responsáveis pela violação de tais direitos e liberdades. Isso significa, em última análise, que as obrigações positivas irrigam a atuação do Estado em todas suas fisionomias de poder, retratáveis nas ações dos Poderes Legislativo, Executivo e Judiciário.

A natureza das medidas a serem adotadas na proteção desses direitos deve encontrar, também no plano do direito internacional dos direitos humanos, uma obediência à proporcionalidade. Essa exigência de proporcionalidade, que nutre, claramente, as Convenções Internacionais, requer que as medidas adotadas na proteção dos direitos e liberdades sejam aquelas "necessárias em uma sociedade democrática" ${ }^{35}$ Isso demanda do Estado, essencialmente, que não intervenha desmesuradamente no direito, seja restringindo onde não deva fazê-lo (proibição do excesso), seja deixando de fazê-lo quando a natureza da agressão e o direito violado o exijam (proibição de proteção insuficiente). Trata-se de uma orientação que vem se consolidando de forma cada vez mais explícita na jurisprudência da Corte Interamericana de Direitos Humanos e do Tribunal Europeu de Direitos Humanos, que já houveram por declarar que em situações determinadas, para fazer efetiva a tutela dos direitos, o Estado deve sancionar penalmente àqueles que cometam agressões contra os bens protegidos pelas respectivas Convenções (intimidade, honra, vida privada, etc). ${ }^{36}$

\section{CONCRETIZAÇÕES DOS DEVERES DE PROTEÇÃO JURÍDICO- PENAL NA JURISPRUDÊNCIA DOS TRIBUNAIS INTERNACIONAIS DE DIREITOS HUMANOS}

4.1. O Convênio Europeu para a Proteção dos Direitos Humanos e Liberdades Fundamentais (CEDH, 4.11.1950) e a Jurisprudência do Tribunal Europeu de Diretos Humanos (TEDH)

A reiterada jurisprudência do TEDH indica no sentido de que os Estados têm obrigações positivas, nas esferas legislativa, administrativa e judicial, voltadas a garantir o efetivo respeito aos direitos consagrados no respectivo Convênio. No que toca ao direito à vida, por exemplo, consagrado no art. $2^{\circ}$ do $\mathrm{CEDH}$, a Corte Européia definiu com clareza que "os Estados tem o dever primordial de assegurar o direito à vida, estabelecendo uma legislação penal tendente a dissuadir a prática de atentados às pessoas, a qual encontre apoio em um mecanismo de prevenção, repressão

\footnotetext{
${ }^{35}$ Fórmula repetidamente utilizada na Convenção Americana de Direitos Humanos e no Convênio Europeu de Direito Humanos, indicando, em gênero, os limites e possibilidades de exercício dos direitos por elas reconhecidos e de suas correlatas medidas restritivas.

${ }^{36}$ Veja-se, a respeito, o estudo de DOMÉNECH PASCUAL, Gabriel, Derechos Fundamentales y Riesgos Tecnológicos. Madrid: Centro de Estúdios Políticos y Constitucionales, 2006.
} 
e sanção de agressões dessa natureza”, ${ }^{37}$

À luz da jurisprudência do TEDH, tais obrigações positivas podem implicar a adoção de medidas que não se voltem apenas contra a arbitrariedade do poder público, senão que devem projetar-se, também, no seio das relações entre particulares.

O Caso " $X$ and $Y v$. The Netherlands" é bastante elucidativo no que respeita ao diagnóstico do TEDH acerca da responsabilidade estatal por insuficiência de proteção. A situação de fato apontava que " $Y$ ", uma deficiente mental, no dia seguinte ao seu décimo sexto aniversário, fora sexualmente violada no interior de uma instituição reservada a pessoas acometidas de moléstias dessa natureza. Sucedia que a legislação local exigia, para vítimas com idade superior a 16 anos, a iniciativa da própria ofendida (equivalente à representação do ofendido, no exemplo do direito brasileiro), hipótese logicamente inviável no caso concreto em face do déficit apresentado pela vítima (mentalmente, considerada uma criança). Diante da incapacidade de " $Y$ ”, " $X$ ”, seu pai, apresentou a denúncia (representação) perante a polícia e o promotor locais. Os Tribunais holandeses consideraram, ao final, que o silêncio do legislador não poderia ser suprido por uma interpretação analógica (in malam partem), de sorte que o autor da agressão sexual resultou absolvido. " $X$ ” recorreu dessa decisão ao TEDH. Essa Corte reconheceu que: a) no caso, estavam em questão valores essenciais da vida privada; b) que medidas civis se constituíam como uma resposta insuficiente à modalidade de agressão sofrida por " $Y$ ”, e c) que apenas sanções penais seriam adequadas para dissuadir a prática de fatos daquela gravidade. Em face disso, o TEDH, estimando que a legislação local era insuficiente à proteção efetiva da vítima, condenou a Holanda por violação ao art. $8^{\circ}$ do Convênio Europeu de Direitos Humanos ${ }^{38}$, determinando, como medida reparatória aplicável nos limites de sua competência, que o Estado indenizasse a vítima. ${ }^{39}$

4.2. A Convenção Americana sobre Direitos Humanos (CADH, 22.11.1969) e a Jurisprudência da Corte Interamericana de Diretos Humanos (CIDA)

A Convenção Americana sobre Direitos Humanos - Pacto de São José da Costa Rica, promulgada no Brasil por meio do Decreto $n^{\circ} 678$ (6.11.1992), é o documento normativo por meio do qual os Estados-Partes se obrigam a lutar contra as violações de direitos humanos havidas no âmbito de suas respectivas áreas territoriais (“jurisdições”),

\footnotetext{
${ }^{37}$ No original: "It is common ground that the State's obligation in this respect extends beyond its primary duty to secure the right to life by putting in place effective criminal-law provisions to deter the commission of offences against the person backed up by law-enforcement machinery for the prevention, suppression and sanctioning of breaches of such provisions" (Case of Osman v. The United Kingdom 87/1997/871/1083 - 28.10.1998).

${ }^{38}$ Art. 8. Derecho al respeto a la vida privada y familiar. 1. Toda persona tiene derecho al respeto de su vida privada y familiar, de su domicilio y de su correspondencia. 2. No podrá haber injerencia de la autoridad pública en el ejercicio de este derecho, sino en tanto en cuanto esta injerencia esté prevista por la ley y constituya una medida que, en una sociedad democrática, sea necesaria para la seguridad nacional, la seguridad pública, el bienestar económico del país, la defensa del orden y la prevención del delito, la protección de la salud o de la moral, o la protección de los derechos y las libertades de los demás.

39 "27. The Court finds that the protection afforded by the civil law in the case of wrongdoing of the kind inflicted on Miss $Y$ is insufficient. This is a case where fundamental values and essential aspects of private life are at stake. Effective deterrence is indispensable in this area and it can be achieved only by criminallaw provisions; indeed, it is by such provisions that the matter is normally regulated".
} 
adotando todas as ações necessárias à investigação e punição daqueles que tenham praticado atentados dessa ordem. Ao aderirem ao Pacto, os países comprometem-se perante a comunidade internacional a se submeterem à jurisdição da Corte Interamericana de Direitos Humanos, que aplica diretamente a Convenção, assumindo deveres de proteção e de adoção de disposições de direito interno para tornar efetivos os diretos e liberdades reconhecidos na Convenção.

No que diz respeito aos direitos nela reconhecidos, e muito especialmente à vida humana, a Convenção dispõe, em título dedicado aos "Deveres dos Estados e Direitos Protegidos”, no Capítulo I (“Enumeração de Deveres”):

Obrigação de respeitar os direitos

Art. $1^{\circ}$. 1. Os Estados-Partes nesta Convenção comprometem-se a respeitar os direitos e liberdades nela reconhecidos e a garantir seu livre e pleno exercício a toda pessoa que esteja sujeita à sua jurisdição, sem discriminação alguma por motivo de raça, cor, sexo, idioma, religião, opiniões políticas ou de qualquer outra natureza, origem nacional ou social, posição econômica, nascimento ou qualquer outra condição social.

Dever de adotar disposições de direito interno

Art. $2^{\circ}$ - Se o exercício dos direitos e liberdades mencionados no art. $1^{\circ}$ ainda não estiver garantido por disposições legislativas ou de outra natureza, os Estados-Partes comprometem-se a adotar, de acordo com as suas normas constitucionais e com as disposições desta Convenção, as medidas legislativas ou de outra natureza que forem necessárias para tornar efetivos tais direitos $e$ liberdades.

O Caso Velásquez Rodriguez, um dos tantos respeitantes às recorrentes desaparições forçadas verificados na América Latina, é de grande transcendência para a apreciação da jurisprudência da Corte na aplicação da CADH. A Corte assentou explicitamente que o art. 1.1. "impõe aos Estados-Partes os deveres fundamentais de respeito e de garantia, de modo que todo menoscabo aos direitos humanos reconhecidos na Convenção que possa ser atribuído (...) a uma ação ou omissão de qualquer autoridade pública constitui um fato imputável ao Estado”. Assim, a primeira obrigação assumida pelos Estados, nos termos do referido dispositivo, é a de "respeitar os direitos e liberdades" reconhecidos na Convenção. Como conseqüência dessa obrigação, “os Estados devem prevenir, investigar e sancionar toda violação de direitos humanos reconhecidos pela Constituição”, além de buscar o restabelecimento, se possível, do direito afetado e, eventualmente, propiciar a reparação dos danos produzidos pela violação dos direitos humanos. Em síntese, o Estado encontra-se no "dever jurídico de prevenir, razoavelmente, as violações de direitos humanos, de investigar seriamente com os meios a seu alcance as violações de tenham sido cometidas no âmbito de sua jurisdição a fim de identificar os responsáveis, de impor-lhes as sanções pertinentes e de assegurar à vítima uma adequada reparação. ${ }^{40}$

${ }^{40}$ CIDH - Caso Velásquez Rodriguez (Sentença de 29.07.1988, §§ 164, 165, 166 e 174). 


\section{O DESFECHO DO CASO DAMIÃO NA CORTE INTERAMERICANA DE DIREITOS HUMANOS}

O Caso Damião foi, enfim, levado a julgamento perante a Corte Interamericana de Direitos Humanos (CIDH), a fim de que essa decidisse se o Estado era responsável pela violação dos direitos consagrados nos arts. $4^{\circ}$ (Direito à Vida), $5^{\circ}$ (Direito à Integridade Pessoal), $8^{\circ}$ (Garantias Judiciais) e 25 (Proteção Judicial) da Convenção Americana, tudo com relação à obrigação estabelecida no art. 1.1 (Obrigação de respeitar os direitos) do mesmo instrumento, em detrimento de Damião, isso: a) pelas condições desumanas e degradantes da sua hospitalização, pelos golpes e ataques contra a integridade pessoal de que fora vítima por parte dos funcionários da Casa de Repouso Guararapes; b) por sua morte enquanto se encontrava ali submetido a tratamento psiquiátrico; c) bem como pela falta de adequada investigação e garantias judiciais que caracterizam seu caso e o mantém na impunidade.

Em decisão final, a CIDH condenou o Brasil por violar, em detrimento do cidadão brasileiro Damião Ximenes Lopes, seus direitos à vida e à integridade pessoal consagrados nos arts. $4.1^{41}$, 5.1 e 5.2 da CADH, em relação com a obrigação geral (de respeitar e garantir esses mesmos direitos) estabelecida no art. 1.1 da Convenção. De igual forma, a CIDH reconheceu violados os arts. $8.1^{42}$ e $25.1^{43}$ da Convenção, em relação com o mesmo art. 1.1, em detrimento das familiares da vítima.

Nas razões de sua decisão, a CIDH asseverou que: "os Estados têm o dever de investigar as afetações aos direitos à vida e à integridade pessoal como condição para garantir esses direitos". Apontou, ainda, que o Brasil "falhou em seus deveres de respeito, prevenção e proteção", considerando-o, pois, "responsável pela violação do direito à vida e à integridade pessoal" da vítima (\$177). ${ }^{44}$

No que respeita à demora do processo, a CIDH fez constar que esta se deveu à letargia conduta das autoridades judiciais, tendo o Ministério Público apresentado denúncia em março de 2000, sem que até então (2006) houvesse pronunciamento definitivo em primeira instância. Segundo a Corte, "está provado que a Terceira Vara da Comarca de Sobral demorou mais de dois anos para realizar as audiências destinadas a ouvir as declarações de testemunhas e informantes e, em alguns períodos, não realizou atividade alguma com vistas à conclusão do processo" (\$199). Outrossim, anotou que o Ministério Público "tardou mais de três anos para aditar a denúncia" para a inclusão de co-autores. Asseverou a CIDH, na oportunidade, que "o Ministério

\footnotetext{
${ }^{41}$ Artigo $4^{o}$. 1 . Toda pessoa tem o direito de que se respeite sua vida. Esse direito deve ser protegido pela lei e, em geral, desde o momento da concepção. Ninguém pode ser privado da vida arbitrariamente.

${ }^{42}$ Artigo $8^{\circ}$. Garantias judiciais. 1. Toda pessoa tem direito a ser ouvida, com as devidas garantias e dentro de um prazo razoável, por um juiz ou tribunal competente, independente e imparcial, estabelecido anteriormente por lei, na apuração de qualquer acusação penal formulada contra ela, ou para que se determinem seus direitos ou obrigações de natureza civil, trabalhista, fiscal ou de qualquer outra natureza. ${ }^{43}$ Artigo $25^{\circ}$. Proteção judicial. 1 . Toda pessoa tem direito a um recurso simples e rápido ou a qualquer outro recurso efetivo, perante os juízes ou Tribunais competentes, que a proteja contra atos que violem seus direitos fundamentais reconhecidos pela Constituição, pela lei ou pela presente Convenção, mesmo quando tal violação seja cometida por pessoas que estejam atuando no exercício de suas funções oficiais.

${ }^{44}$ CIDH - Caso Ximenes Lopes versus Brasil (Sentença de 04.07.2006).
} 
Público é um órgão do Estado, motivo por que suas ações e omissões podem comprometer a responsabilidade internacional desse mesmo Estado" (§200). ${ }^{45}$

A modo de dispositivo, a CIDH decidiu que "os familiares de vítimas de violações de direitos humanos têm o direito a um recurso efetivo. O conhecimento da verdade dos fatos em violações de direitos humanos como as deste caso é um direito inalienável e um meio importante de reparação para a suposta vítima e, quando cabível, para seus familiares, além de constituir uma forma de esclarecimento fundamental para que a sociedade possa desenvolver mecanismos próprios de desaprovação e prevenção de violações como essas no futuro" (§245). Em conseqüência disso, "os familiares das vítimas têm o direito, e os Estados têm a correspondente obrigação, a que o ocorrido seja "efetivamente investigado" pelas autoridades estatais, a que se inicie um processo contra os supostos responsáveis por esses ilícitos e, se for o caso, de que lhes "sejam impostas as sanções pertinentes" (§246). Assim, considerando que "transcorridos mais de seis anos dos fatos, os autores dos tratamentos cruéis, desumanos e degradantes, bem como da morte de Damião Ximenes Lopes, não foram responsabilizados, prevalecendo a impunidade”, a Corte, ao condenar o Estado brasileiro, advertiu que:

248. “(...) o Estado deve garantir que em um prazo razoável o processo interno destinado a investigar e sancionar os responsáveis pelos fatos deste caso surta seus devidos efeitos”, conferindo aplicabilidade direta no direito interno às normas de proteção da Convenção Americana.

\section{CONSIDERAÇÕES CONCLUSIVAS}

Em linhas derradeiras, e a título de síntese, podemos reconhecer que se o legado do tempo de Damiens foi a problematização de um Direito penal ilustrado, com a imposição de evidentes freios à ação estatal arbitrária e excessiva, o legado do tempo de Damião haverá de ser a séria reproblematização de um Direito penal que, partindo dessas bases iluministas há muito consolidadas, rejeite a insuficiência e a letargia estatais, tomando a sério a proteção efetiva de direitos humanos e fundamentais.

Trata-se, enfim, de evidenciar, na tutela dos direitos fundamentais, uma situação de equilíbrio entre a Constituição e a legislação, tudo sob o olhar atento, e não menos equilibrado, da jurisdição constitucional. Um equilíbrio - como anota Manuel Aragón “que no tiene por qué redundar en perjuicio sino, por el contrario, en beneficio de la garantía de los derechos, establecendose una tutela que tampoco conviene distorsionar, ni por defecto ni por exceso". ${ }^{46}$

Dessa ambivalência funcional do Direito penal, enquanto instrumento auxiliar na tutela de direitos humanos e fundamentais, resulta que limites máximos de intervenção podem conviver com limites mínimos nesse sentido, porquanto, como manifestamos alhures (FELDENS: 2005), um Direito penal de intervenção necessariamente mínima não se contrapõe conceitualmente a um Direito penal de intervenção minimamente necessária.

${ }^{45}$ CIDH - Caso Ximenes Lopes versus Brasil (Sentença de 04.07.2006).

${ }^{46}$ Abordando o tema sob o foco do "lugar de ley en la regulación de los derechos fundamentales: equilibrio entre Constitución, legislación y jurisdicción”: ARAGÓN REYES, Manuel, Estudios de Derecho Constitucional, Madrid: Centro de Estudios Políticos y Constitucionales, 1998, p. 161. 
Por encerrar com Kaufmann... "es una ley estructural de nuestro ser, generalmente a tener en cuenta, aunque también muchas veces olvidada, que en nuestro mundo no se pueden llevar las condiciones al extremo sin que esto se vuelva en su contra y sin que, por eso mismo, las posturas extremas, en tanto parecen enfrentarse entre sí, se contrapongan como teorías complementarias. Por eso, los teoremas extremos tienen algo irreal y utópico en sí mismos”. ${ }^{7}$

${ }^{47}$ KAUFMANN, Arthur. Derecho, Moral y Historicidad, trad. Emilio Eiranova Encinas, Madrid-Barcelona: Marcial Pons: 2000, p. 48-49. 